\title{
Ordenando la política de auspicios académicos del Colegio Médico del Perú
}

\section{Ordering academic auspices policy of the Medical College of Peru}

Correspondencia Jaime Morán Ortiz jmoranortiz@gmail.com

Recibido: 06/06/2016 Aprobado: 15/06/2016

Citar como: Palacios-Celi M, Moran-Ortiz J. Ordenando la política de auspicios académicos del Colegio Médico del Perú. Acta Med Peru. 2016;33(2):157-8
Miguel Palacios-Celi ${ }^{1}$, Jaime Moran-Ortiz ${ }^{2}$

1 Decano Nacional, Consejo Nacional, Colegio Médico del Perú. Lima, Perú.

2 Sistema de Certificación y Recertificación del Médico Cirujano y Médicos Especialistas (SISTCERE), Colegio Médico del Perú. Lima, Perú.

\section{Sr. Editor:}

Hemos recibido la carta de Zevallos-Morales et al. [1] en relación a algunos cursos con terapias pseudocientíficas que han sido auspiciados en la gestión anterior del Colegio Médico del Perú (CMP), al respecto es necesario contextualizar la función del CMP y su vínculo con la Medicina Tradicional, Alternativa y/o Complementaria (MTAC), antes de informar de las acciones realizadas.

El ejercicio profesional del médico en el Perú se rige por el Código de Ética y Deontología del CMP, el cual contiene un conjunto de orientaciones y preceptos cuyo cumplimiento garantiza un ejercicio profesional basado en el conocimiento científico y en el permanente respeto a los derechos de los pacientes [2]. Sin embargo, debe asumir nuevos desafíos ante el permanente desarrollo de la medicina, de la biología y la biotecnología, la expansión de la industria farmacéutica y los medios diagnósticos, la desinformación en la población y la creciente amenaza de grupos que promueven las pseudociencias.

Con Ley N. ${ }^{\circ} 15173$ del 16 de octubre de 1964, se crea el Colegio Médico del Perú (CMP), el cual precisa en su artículo 5, que constituyen fines de la Orden, entre otros, el velar para que el ejercicio profesional se cumpla de acuerdo con las normas deontológicas contenidas en el Código de Ética profesional que el CMP dicte; propender a mejorar la salud individual y colectiva de los habitantes del país; contribuir al avance de la ciencia médica y cooperar con los poderes del Estado en la defensa de la salud, procurando que la asistencia facultativa alcance a todo el país [3]. Por ello, desde que el CMP inició su funcionamiento en 1969, se ha esmerado en el cumplimiento de sus fines, contribuyendo al mejoramiento de la salud individual y colectiva a través de diversas acciones desarrolladas por su Consejo Nacional y los diferentes comités o grupos de trabajo que participan de la gestión institucional.

En el marco de la Ley de Salud № 26842, que en su artículo 17 señala: "La promoción de la medicina tradicional es de interés y atención preferente del Estado" [4], así como de la Estrategia Global sobre Medicina Tradicional de la Organización Mundial de la Salud que reporta un alto porcentaje de la población mundial ha utilizado alguna vez en su vida la medicina tradicional, por ejemplo $42 \%$ en EE UU, 48\% en Australia, 70\% en Canadá, 75\% en Francia, entre otros [5]. El CMP decidió conformar en marzo de 2006 el Comité de Medicina Tradicional, Alternativa y/o Complementaria con la finalidad de contribuir con recomendaciones y propuestas de normatividad y regulación de la MTAC. Si bien, 
este grupo de trabajo viene realizando denodados esfuerzos a través de diversas actividades educativas, de investigación y de sensibilización sobre los diversos enfoques de la MTAC y su articulación con los sistemas de salud, existe también grupos de interés que hacen uso indiscriminado y poco responsable de supuestos métodos terapéuticos alternativos sin el correspondiente control y regulación, lo cual conlleva a un enorme riesgo para la salud de la población.

El CMP, a través del Sistema de Certificación y Recertificación del Médico Cirujano y Médico Especialista (SISTCERE), tiene dentro de sus funciones la evaluación de los cursos que solicitan ser avalados por la institución, cuyo accionar en esta gestión 2016-2017 ha doblegado esfuerzos para discernir entre aquellos eventos donde se promueven prácticas cuya eficacia se haya demostrado científicamente, y diferenciarlos de aquellos cuyas prácticas se encuentren inspiradas en la charlatanería, carentes de base científica y que proponen procedimientos ilusorios o insuficientemente probados, los cuales se proponen como eficaces, pues cada una de las técnicas y terapias no convencionales deberá demostrar y/o avalar científicamente su eficacia, efectividad, eficiencia, calidad y seguridad para que puedan ser reconocidas por la institución y poder ser promovidas y extendidas a la comunidad médica nacional.

Es así que el SISTCERE hasta fines del mes de junio de 2016, ha recibido en total 390 solicitudes de instituciones que organizan eventos científicos para otorgarles el creditaje respectivo válido para la recertificación médica. Hasta la fecha, se ha emitido 273 resoluciones con el creditaje correspondiente, sin embargo a 8 de estas solicitudes se les ha denegado el mismo por tratar temas que no promueve el CMP, como por ejemplo aquellas terapias que carecen de evidencias científicas sobre su eficacia y utilidad [1]. Otros rechazos se han producido por corresponder a cursos o diplomados organizados por instituciones no acreditadas.
La actual gestión del CMP se ha propuesto corregir prácticas de promoción o difusión de eventos científicos cuyo contenido no tenga la suficiente evidencia científica [1], sean ajenos a sus fines institucionales o que contribuyan al intrusismo médico de otras profesiones o al intrusismo dentro de las mismas especialidades médicas, un ejemplo de lo último, la reciente creación del Comité de Lucha contra el Intrusismo Profesional.

\section{Fuente de financiamiento:}

Los autores declaran no haber recibido ninguna financiación para la realización de este trabajo.

\section{Declaración de conflicto de intereses:}

Los autores declaran no tener conflicto de intereses con la publicación de este artículo.

\section{REFERENCIAS BIBLIOGRÁFICAS}

1. Zevallos-Morales A, Quiñones-Laveriano DM, Taype-Rondan A. Cursos de terapias pseudocientíficas auspiciados por el Colegio Médico del Perú. Acta Med Peru. 2016;33(2):155-6.

2. Colegio Médico del Perú. Código de Ética y Deontología. Lima: CMP; 2007

3. Congreso de la República del Perú. Ley N. ${ }^{\circ}$ 15173. Ley de creación del Colegio Médico del Perú como entidad autónoma de derecho público interno. Lima: Congreso de la República; 1964.

4. Congreso de la República del Perú. Ley N. ${ }^{\circ}$ 26842. Ley General de Salud. Lima: Congreso de la República; 1997.

5. Organización Mundial de la Salud. Estrategia de la OMS sobre medicina tradicional 2002-2005. Ginebra: OMS; 2002. 